\title{
Deguanylation of Guanine Based-Nucleosides and Calf Thymus DNA Induced by Halogenated Alkanes at the Physiological Condition
}

\author{
Jyoti Sherchan and Eung-Seok Lee* \\ College of Pharmacy, Yetngnam Liniversity, Kyongsan 712-749, Korea. * E-mail: eslee ânhuac.kr \\ Received September + . 2009. Accepted October 9.2009
}

\begin{abstract}
Massive deguanylation of guanine based-nucleosides induced by halogenated alkanes at the phy siological condition have been observed. For the study of deguany lation effects by the different substituents and/or functionality in halogenated alkanes, diverse kinds of halogenated alkanes were incubated with guanine based-nucleosides (ddG, $\mathrm{dG}$ and guanosine) for $48 \mathrm{~h}$ at the physiological condition ( $\mathrm{pH} 7,4,37^{\circ} \mathrm{C}$ ), which were analyzed by HPLC and further confirmed by LC-MS. Annong the sixteen different halogenated alkanes, we observed massive deguanylation of nucleosides by 2-brono-2-methy lpropane, 2,3-dibromopropene, 2-bromopropane, bromoethane and 2-iodopropane. The order of deguanylation rate was highest in 2-brono-2-nethy lpropane followed by 2,3-dibromopropene, 2-bromopropane, bromoethane and 2-iodopropane. In addition, time and dose response relationship of deguanylation in guanine basednucleosides induced by 2-bromo-2-methylpropane, 2,3-dibromopropene, 2-bromopropane bromoethane and 2-iodopropane at the physiological condition were investigated. Deguany lation of calf thymus DNA induced by halogenated alkanes was also investigated. These results suggest that the toxic effect of certain halogenated alkanes might be from the depurination of nucleosides.
\end{abstract}

Key Words: Deguanylation. Depurination, Halogenated alkanes, Guanine base-nucleosides, Calf thymus DNA

\section{Introduction}

The depurination or deguanylation of nucleic acids. which involve the release of purine or guanine bases. respectively. from mucleic acids by hydrolysis of the $\mathrm{N}$-gly cosidic bond (Fig. 1). gives rise to alterations of the cell genome. ${ }^{1,2}$ Although depurination occurs spontaneously under physsiological conditions. the rate of depurination is accelerated at low $\mathrm{pH}$. high temperature, or by alkylation. ${ }^{3}$ Since the apurinic sites resulting from depurination have shown lethality ${ }^{4.3}$ and base substitution errors. depurination (deguanylation) could be one of the promising novel mechanisms of toxicity induced by the short chain halogenated alkanes.

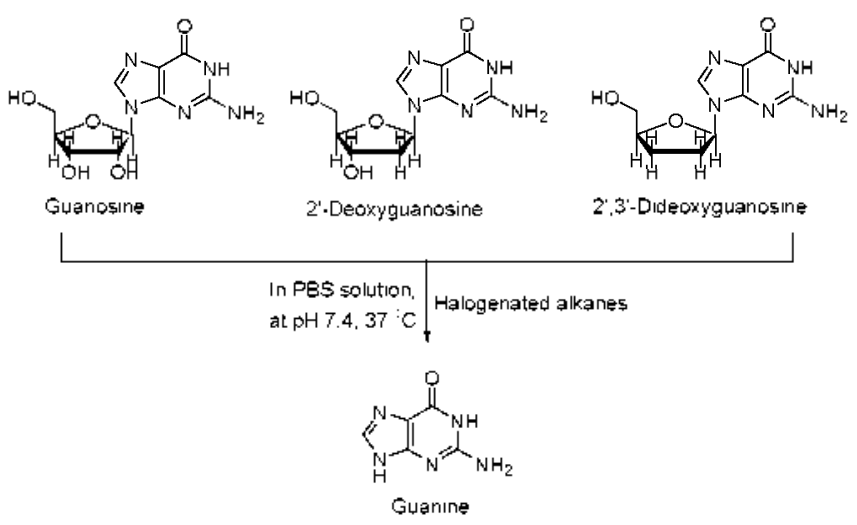

Figure 1. Scheme of deguanylation, the release of guanine bases from nucleic acids by hydrolysis of the V-glycosidic bond. Guanine basednucleosides were incubated with 16 halogenated alkanes at the phrsiological condition ( $\mathrm{pH} 7,4,37^{\circ} \mathrm{C}$ ) for a certain period and analyzed by HPLC, LC-MS and UV.
Previously. we observed the massive depurination of nucleosides such as 2'.3'-dideosyadenosine (ddA), 2'-deosyadenosine (dA). $2^{\prime}, 3^{\prime}$-dideoxyguanosine (ddG), $2^{\circ}$-deoxyguanosine (dG). and calf thy mus DNA with an excess anount of 2-bromopropane (2-BP) at the phy'siological condition. ${ }^{6}$ Also we observed the massive deadenylation of adenine based-nucleosides such as ddA. dA. and calf thy mus DNA with excess amount of halogenated alkanes at the physiological condition. ${ }^{3}$ It would be very interesting to investigate deguanylation of guanine basedmucleosides induced by halogenated alkanes according to the difference of substituents and/or functionality in halogenated alkanes. which may provide valuable information for the mechanism of toxicity of halogenated alkanes. In addition, it would also be interesting to compare the rate of depurination between guanine based-nucleosides and adenine based-nucleosides. as guanine has been reported to release more rapidly than adenine. ${ }^{3}$

In colmection with previous studies, diverse kinds of halogenated alkanes were incubated with guanine based-nucleosides (ddG. $\mathrm{dG}$ and guanosine) for $48 \mathrm{~h}$ at the phy'siological condition $\left(\mathrm{pH} 7.4,37^{\circ} \mathrm{C}\right.$ ), which were analyzed by HPLC and further confirmed by LC-MS for the study of deguanylation effects by different substituents of and/or functionality in halogenated alkanes. Short-chain halogenated alkanes. which we utilized for the study of deguanylation of guanine based-nucleosides, have been widely used industrially as chemical internediates, extraction solvents. degreasing compounds. copolymer cross-linking agents. or have been reported to be nutagenic and carcinogenic. ${ }^{8-1}$ : Among the sixteen different halogenated alkanes. we observed massive deguanylation of nucleosides by 2-bromo2-methylpropane (2-B-2-MP), 2.3-dibromopropene (2.3-dBPe). 2-bromopropane (2-BP). bromoethane (BE) and 2-iodopropane (2-IP). 


\section{Materials and Methods}

Chemicals. Iodomethane $(99.5 \%)$, bromoethane $(\geq 99 \%)$. iodoethane (99\%). 1,2-dibromoethane (99+\%), 1,2-dichloroethane $(99.8 \%)$. I-bromopropane $(99 \%)$. 2-bromopropane $(99$ $\%$ ), 1-chloropropane (98\%), 2-chloropropane (99+\%). 1-iodopropane (99\%). 2-iodopropane (2-IP, 99\%), 1,2-dibromopropane (97\%). 1.3-dibromopropane. 1.2,3-tribromopropane $(97$ $\%) .2 .3$-dibromopropene (>99\%). 2 -deoxyguanosine hy drate $(99 \%)$, guanosine hydrate $(98 \%)$, calf-thymus DNA (deosy ribonucleic acid sodium salt, from calf thy mus). 5-fluorouracil (99\%). phosphate buffered saline ( $\mathrm{pH} 7.4)$ and ammonium acetate $(99.995+\%)$ were purchased from Sigma Aldrich Co. (ST. Louis. MO). 2*3'-Dideoxyguanosine and 2-bromo-2-methỵlpropane ( $\geq 97 \%$ ) were obtained from Berry \& Associates Inc and Fluka respectively. 9-Methyl adenine (9-MA) was obtained by synthesis in the present lab. HPLC grade acetonitrile and methanol was purchased from World Science, Korea. All other chemicals if not mentioned. were also obtained from Sigma Aldrich Co. (ST. Louis, MO).

Preliminary reactions. One mg of nucleoside (ddG. dG and guanosine) was dissolved in $1 \mathrm{~mL}$ phosphate buffered saline solution (PBS) in $5 \mathrm{~mL}$ vial. Ten $\mu \mathrm{L}$ ( $5 \mathrm{mg}$ in $1 \mathrm{~mL}$ PBS) of 5 flurouracil (5-FU) was added as an internal standard. It was then incubated with an excess amount (512 equivalents) of each of the sixteen halogenated alkanes listed in Table 1 at $37^{\circ} \mathrm{C}$ for $48 \mathrm{~h}$, respectively. It was analyzed by HPLC and further confirmed by LC-MS. All the reactions were repeated for three times.

Time response reaction. One mg of nucleoside (ddG, dG and guanosine) was dissolved separately in $1 \mathrm{~mL}$ phosphate buffered saline solution (PBS) in $5 \mathrm{~mL}$ vial. Ten $\mu \mathrm{L}$ ( $5 \mathrm{mg}$ in $1 \mathrm{~mL}$ PBS) of 5-flurouracil (5-FU) was added as an internal standard. It was then incubated with 512 equivalents of $2.3-\mathrm{dBPe}, 2-\mathrm{BP}$. $\mathrm{BE}$ and $2-\mathrm{PP}$ for ddG and dG. 4 equivalents of $2-\mathrm{B}-2-\mathrm{MP}$ for ddG. 32 equivalents of 2-B-2-MP for dG. 512 equivalents of 2-B-2-MP for guanosine. respectively, at $37^{\circ} \mathrm{C}$. About $10 \mu \mathrm{L}$ of samples were withdrawn at certain time intervals and analyzed by HPLC until 100\% deguanylation occurred. All the reactions were repeated for three times.

Dose response reaction. One mg of nucleoside (ddG. $\mathrm{dG}$ and guanosine) was dissolved separately in $1 \mathrm{~mL}$ phosphate buffered saline solution (PBS) in $5 \mathrm{~mL}$ vial. Ten $\mu \mathrm{L}$ ( $5 \mathrm{mg}$ in $1 \mathrm{~mL}$ PBS) of 5 -fluorouracil ( 5 -FU) was added as an intemal standard. It was then incubated with different amounts $(0.2,4,8.16 .32$. $64,128.256$ and 512 equivalents) of 2.3-dBPe, 2-BP. BE and 2-IP at $37^{\circ} \mathrm{C}$ for a time period in which $100 \%$ deguanylation occurred. For incubation with 2-B-2-MP different amounts $\left(0,1,2.3\right.$ and 4 equivalents for $\mathrm{ddG}_{2} 0.2,4,8,16$ and 32 equivalents for dG. $0,2,4,8,16,32,64,128,256$ and 512 equivalents for guanosine) were employed. Again the samples were analyzed by HPLC and repeated for three times.

Reactions with Calf-thymus DNA (ct-DNA). Two mg of ctDNA was dissolved in $20 \mathrm{~mL}$ of PBS solution and $40 \mu \mathrm{L}$ of 9 . methyl adenine ( $0.5 \mathrm{mg}$ in $\mathrm{I} \mathrm{mL}$ PBS) was added as an internal standard and stirred to mix properly. One $\mathrm{mL}$ of the above prepared solution of ct-DNA was taken in $5 \mathrm{~mL}$ vial and incubated with $128 \mu \mathrm{L}$ of $2-\mathrm{B}-2-\mathrm{MP}$. 2,3-dBPe, 2-BP. BE and $2-\mathrm{IP}$ at the
Table 1. List of halogenated alkanes with their chemical structure and molecular weight

\begin{tabular}{|c|c|c|c|}
\hline No. & Halogenated alkanes & Structure & Mol. ut \\
\hline 1 & Iodomethane (IM) & $-\mathrm{I}$ & 141.94 \\
\hline 2 & Bromoethane $(\mathrm{BE})$ & & 108.97 \\
\hline 3 & Iodoethane (IE) & & 155.97 \\
\hline 4 & 1,2-dibromoethane $(1,2-\mathrm{dBE})$ & & 187.86 \\
\hline 5 & 1,2-dichloroethane $(1,2-\mathrm{dCE})$ & & 98.96 \\
\hline 6 & 1-bromopropane (l-BP) & & 122.99 \\
\hline 7 & 2-bromopropante (2-BP) & & 122.99 \\
\hline 8 & 1-chloropropane (1-CP) & & 78.54 \\
\hline 9 & 2-chloropropane (2-CP) & & 78.54 \\
\hline 10 & 1-iodopropane (I-IP) & & 169.99 \\
\hline 11 & 2-iodopropane (2-IP) & & 169.99 \\
\hline 12 & 1.2-dibromopropane (1.2-dBP) & & 201.89 \\
\hline 13 & 1,3-dibromopropane $(1,3$-dBP) & & 201.89 \\
\hline 14 & 2-bromo-2methy lpropane (2-B-2-MP) & & 137.03 \\
\hline 15 & 1,2,3-tribromopropane (1,2,3-tBP) & & 280.78 \\
\hline 16 & 2,3-dibromopropene (2,3-dBPe) & & 199.8 \\
\hline
\end{tabular}

physiological condition for $48 \mathrm{~h}$ as a preliminary reaction. At the end of the reaction $300 \mu \mathrm{L}$ of $1 \mathrm{M} \mathrm{HCl}$ was added and centrifuged for $10 \mathrm{~min}$ at $13.000 \mathrm{rpm}$. Then it was analy zed by LCMS under the condition mentioned below

Time response reaction was performed with $128 \mu \mathrm{L}$ of $2-\mathrm{B}-2$ MP. 2,3-dBPe. 2-BP. BE and 2-IP at a time interval of $8 \mathrm{~h}$ for $0,8,16,24,32,40$ and $48 \mathrm{~h}$ at the phy siological condition. respectively. At the end of the reaction $300 \mu \mathrm{L}$ of $1 \mathrm{M} \mathrm{HCl}$ was added and centrifuged for $10 \mathrm{~min}$ at $13.000 \mathrm{~mm}$. Then it was analyzed by LC-MS under the condition mentioned below.

Dose response reaction was performed with $2,4.8,16.32$. 64 and $128 \mu \mathrm{L}$ of 2-B-2-MP. 2,3-dBPe. 2-BP. BE and 2-IP for 48 h at the physiological condition. respectively. At the end of the reaction $300 \mu \mathrm{L}$ of $1 \mathrm{M} \mathrm{HCl}$ was added and centrifuged for 10 min at $13.000 \mathrm{ppm}$. Then it was analyzed by LC-MS under 
the condition mentioned below:

Calculation for deguanylation ratio in nucleosides. Deguanylation ratio (DR. \%) was calculated on the basis of the decreased amount of nucleosides in percentage by comparing the integration value of the nucleosides in HPLC using the formula below:

$$
\text { Deguanỵlation ratio }(\%)=\frac{\frac{A_{0}}{I_{0}}-\frac{A_{L}}{I S_{t}}}{\frac{A_{0}}{I S_{0}}} \times 100 \%
$$

where ' $\mathrm{A}_{0}$ ' is the initial amount of nucleoside; ' $\mathrm{A}_{t}$ ' is the amount of nucleoside after time, $\mathrm{t}$ : 'IS, is the initial amount of internal standard and ' $I S_{\mathrm{t}}$ ' is the amount of nucleoside after time $t$

Calculation for deguanylation ratio in ct-DNA. Deguanylation ratio was calculated on the basis of the increased amount of guanine compared to the internal standard (IS) by comparing the integration value in EIC from LC-MS using the formula below:

\section{Deguanylation ratio $=$ guanine $/$ IS}

Apparatus. HPLC analy ses were performed using two Shimadzu LC-10AT pumps gradient-controlled HPLC system equipped with Shimadzu photo diode array detector (Model SPD-M10A) and dual channel UV detection at $280 \mathrm{~nm}$. Analytes were eluted with a $4.6 \times 250 \mathrm{~mm}, 5 \mu \mathrm{m}$ Waters XTerra ${ }^{2} \mathrm{C}_{18}$ reverse phase analytical column using the following HPLC condition: Isocratically with $4 \%$ acetonitrile in water with 50 $\mathrm{mM}$ ammonium formate at $\mathrm{pH} 6.9 .1 \mathrm{~mL} / \mathrm{min}$ flow rate and 10 $\mu \mathrm{L}$ injection volume for granine-based nucleosides.

ESI LC/MS analyses were performed with a Finnigan LCQ Advantage $(\overrightarrow{\mathrm{B}})$ LC-MS/MS spectrometry utilizing Xcalibur program. The samples were analyzed using $2.1 \times 150 \mathrm{~mm}, 3.5$ $\mu \mathrm{m}$ Waters XTerra ${ }^{2} \mathrm{C}_{18}$ reverse phase analytical column using the following LC condition: Isocratically with $3 \%$ acetonitrile in water with $50 \mathrm{mM}$ ammonium formate at $\mathrm{pH} 6.9,0.18 \mathrm{~mL} /$ min flow rate and $2 \mu \mathrm{L}$ injection volume. The mass spectrometer was operated in the positive polarity mode with ESI source type. Capillary voltage was controlled at $10 \mathrm{~V}$ and $270^{\circ} \mathrm{C}$ and nitrogen gas was used as sheath gas.

Centrifugation was done using Hanil Micro-12 (made in Korea) with maximum capacity $1.5 \mathrm{~mL} \times 12$. maximum speed $13.000 \mathrm{rpm}$. maximum RCF $10.770 \times \mathrm{g}$, and power AC $110 \mathrm{~V}$, $60 \mathrm{~Hz}$.

Statistical analysis. All the reactions were performed at least three times ( $\mathrm{n} \geq 3$ ). The mean value \pm standard error (SE) was determined for each test. Student's t-test was used to compare statistical significance of data. The significant values at either $\mathrm{P}<0.05\left(^{*}\right)$ or $\mathrm{P}<0.01\left(^{* *}\right)$ are represented by asterisks.

\section{Results}

The deguanylation effect of the sixteen halogenated alkanes on guanine based-nucleosides was analyzed by HPLC and further confirmed by LC-MS. Table 1 shows the list of halogenated
Table 2. Preliminary reaction of $d \mathrm{dG}, \mathrm{dG}$ and guanosine with halogenated alkanes at the physiological condition for $48 \mathrm{~h}$

\begin{tabular}{llrrr}
\hline No. & halogenated alkanes & $\begin{array}{c}\text { DR }(\%) \\
\text { in ddG }\end{array}$ & $\begin{array}{c}\text { DR }(\%) \\
\text { in dG }\end{array}$ & $\begin{array}{c}\text { DR }(\%) \text { in } \\
\text { guanosine }\end{array}$ \\
\hline 1 & Iodomethane & \multicolumn{1}{c}{$*$} & \multicolumn{1}{c}{$*$} & $*$ \\
2 & Bromoethane & $\mathbf{1 0 0 . 0 0}$ & 100.00 & 5.28 \\
3 & Iodoethane & 6.30 & 0.84 & 3.49 \\
4 & 1,2-dibromoethane & 6.50 & 1.17 & 7.40 \\
5 & 1,2-dichloroethane & 4.80 & -0.42 & 5.34 \\
6 & 1-bromopropane & 6.90 & -0.18 & 6.70 \\
7 & 2-bromopropane & $\mathbf{1 0 0 . 0 0}$ & 100.00 & 13.66 \\
8 & 1-chloropropane & 5.40 & -0.22 & 7.27 \\
9 & 2-chloropropane & 10.10 & 0.43 & 6.35 \\
10 & 1-iodopropane & 4.80 & -0.08 & 5.96 \\
11 & 2-iodopropane & $\mathbf{1 0 0 . 0 0}$ & $\mathbf{1 0 0 . 0 0}$ & 7.30 \\
12 & 1,2-dibromopropane & 5.90 & 0.01 & 5.69 \\
13 & 1,3-dibromopropane & 2.00 & 2.00 & -0.44 \\
14 & 2-bromo-2methylpropane & $\mathbf{1 0 0 . 0 0}$ & $\mathbf{1 0 0 . 0 0}$ & 100.00 \\
15 & 1,2,3-tribromopropane & 4.20 & -3.49 & 4.69 \\
16 & 2,3-dibromopropene & $\mathbf{1 0 0 . 0 0}$ & $\mathbf{1 0 0 . 0 0}$ & $*$ \\
\hline
\end{tabular}

One $\mathrm{mg}$ of nucleoside (ddG. $\mathrm{dG}$ and guanosine) was dissolyed in $\mathrm{l} \mathrm{mL}$ phospliate buffered saline solution (PBS) in $5 \mathrm{~mL}$ vial. Twenty $\mu \mathrm{L}$ of $5-$ flurouracil ( $10 \mathrm{mg}$ in $1 \mathrm{~mL}$. PBS ) was added as an internal standard. It was then incubated with excess amount ( 512 equivalents) of halogenated alkanes at the pliv siological condition for $48 \mathrm{~h}$. It was analyzed by HPLC and LC-MS. *Only small amount of deguanyled product (guanine) was abserved with many adducts fonmation.

alkanes with chenical structure and molecular weight. which were treated with guanine based-nucleosides. From the preliminary reaction. it was found that $100 \%$ deguanylation occurred in $d d G$ and $d G$ with excess amount ( 512 equivalents) of 2-B-2$\mathrm{MP}, 2,3-\mathrm{dBPe}, 2-\mathrm{BP}, \mathrm{BE}$ and 2-IP at the physiological condition for $48 \mathrm{~h}$ (Table 2). which is described in Figure 2 and 3 . It is interesting to notice that $100 \%$ deguany lation occurred in guanosine with treatment of excess amount (512 equivalents) of 2-B-2-MP at the physiological condition for $48 \mathrm{~h}$. whereas almost no change was observed for adenosine by treatment of all of the sixteen halogenated alkanes at the same condition. In addition, ddG. $d G$ and guanosine were not affected by the other halogenated alkanes.

Analysis of deguanylation of ddG induced by 2-B-2-MP, 2,3-(BBPe, 2-BP, BE and 2-IP by HPLC. Figure 2 shows the HPLC chromatograms under the chromatographic condition described in material and methods for the analy sis of deguanylation of ddG induced by 2-B-2-MP. 2.3-dBPe. 2-BP. BE and 2-IP at $37^{\circ} \mathrm{C}$ for $48 \mathrm{~h}$.

In Figure 2, chronatogram 1 indicates authentic guanine (Gua) at retention time of $4.87 \mathrm{~min}$ and chromatogram 2 indicates the mixture of ddG and 5-fuorouracil (5-FU) utilized as an internal standard at retention times of 12.83 min and 4.12 min. respectively. Guanine, ddG and 5-fuorouracil were well separated from the biological background under the described chromatographic condition. Chromatogram 3.4.5.6 and 7 indicates the mixture after incubation of ddG and excess amount (512 equivalent) of 2-B-2-MP. 2,3-dBPe. 2-BP. BE and 2-IP 


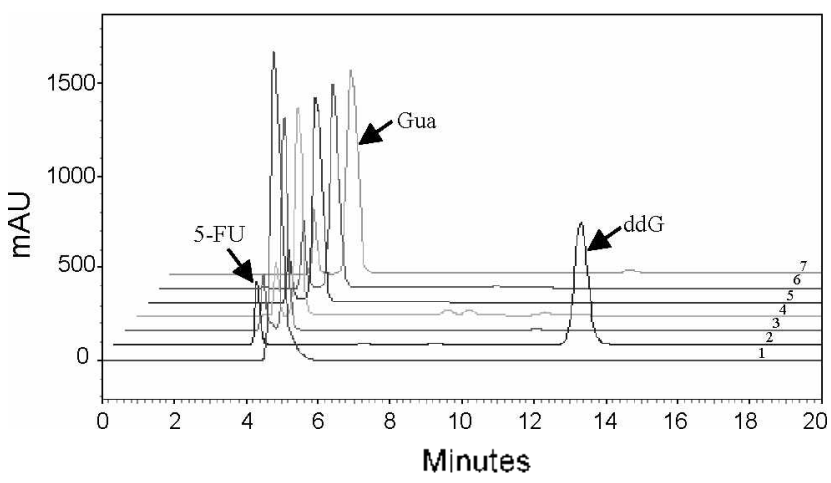

Figure 2. HPLC chromatogram of ( 1 ) gluanine ( Gua), (2) ddG + 5-FU, (3) $\mathrm{ddG}+5-\mathrm{FU}+2-\mathrm{B}-2-\mathrm{MP}(48 \mathrm{~h}),(4) \mathrm{ddG}+5-\mathrm{FU}+2,3-\mathrm{dBPe}(48 \mathrm{~h})$ (5) $\mathrm{ddG}+5-\mathrm{FU}+2-\mathrm{BP}(48 \mathrm{~h})(6) \mathrm{ddG}+5-\mathrm{FU}+\mathrm{BE}(48 \mathrm{~h})(7) \mathrm{ddG}+$ $5-F U+2-I P(48$ h). Retention tine for 5-FU, Gua and ddG were 4. 12 , 4.87 and $12.83 \mathrm{~min}$, respectively, under the HPLC condition mentioned in materials and methods.

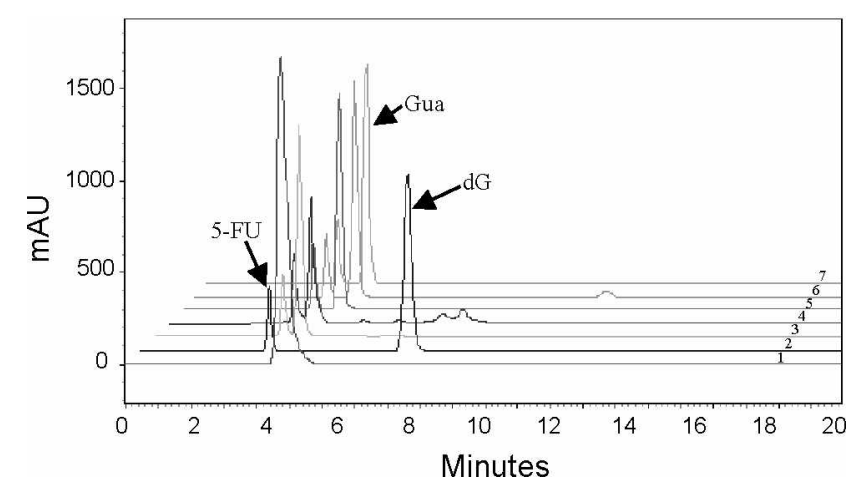

Figure 3. HPLC chromatogram of (1) $\mathrm{Gla},(2) \mathrm{dG}+5-\mathrm{FU},(3) \mathrm{dG}+5-$ $\mathrm{FU}+2-\mathrm{B}-2-\mathrm{MP}(48 \mathrm{~h}),(4) \mathrm{d}(\mathrm{G}+5-\mathrm{FU}+2,3-\mathrm{dBPe}(48 \mathrm{~h})(5) \mathrm{dG}+5-\mathrm{FU}+$ $2-\mathrm{BP}(48 \mathrm{~h})(6) \mathrm{dG}+5-\mathrm{FU}+\mathrm{BE}(48 \mathrm{~h})(7) \mathrm{dG}+5-\mathrm{FU}+2-\mathrm{P}(48 \mathrm{~h})$. Retention time for 5 -FU, Gua and dG were $4.08,4.82$ and $8.38 \mathrm{~min}$, respectively, under the HPLC condition mentioned in materials and methods.

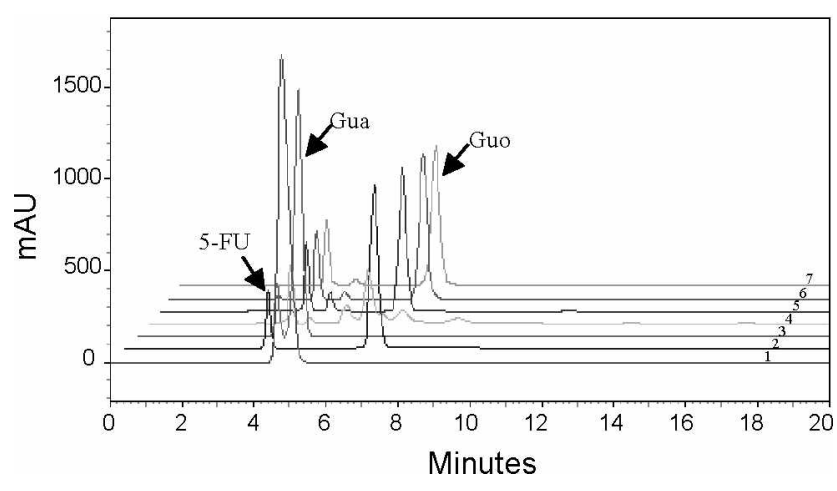

Figure 4. HPLC chromatogran of ( 1 ) Gua, (2) guanosine (Guo ) + 5-FU, (3) Gno + 5-FU + 2-B-2-MP (48 h), (4) Guo + 5-FU + 2,3-dBPe (48 h) (5) Guo $+5-\mathrm{FU}+2-\mathrm{BP}(48 \mathrm{~h})(6) \mathrm{Guo}+5-\mathrm{FU}+\mathrm{BE}(48 \mathrm{~h})(7) \mathrm{Guo}+$ $5-\mathrm{FU}+2-\mathrm{IP}(48 \mathrm{~h})$. Retention time for $5-\mathrm{FU}$, Gua and Guo were 4.06 , 4.76 and $6.70 \mathrm{~min}$, respectively, under the HPLC condition mentioned in materials and methods. for $48 \mathrm{~h}$ at the physiological condition, respectively, which indicates the peak of retention time at 12.83 min. which corresponds to the complete disappearance of ddG and a peak of retention time at 4.87 min, corresponding to the new appearance of guanine. These results indicated that complete deguanylation occurred when ddG was incubated with excess amount of $2-\mathrm{B}$ 2-MP. 2.3-dBPe. 2-BP. BE and 2-IP at $37^{\circ} \mathrm{C}$ for $48 \mathrm{~h}$.

Analysis of deguanylation of dG induced by 2-B-2-MP, 2,3(IBPe, 2-BP, BE and 2-IP by HPLC. Figure 3 shows the HPLC chromatograms under the chromatographic condition described in material and methods. for the analysis of deguanylation of dG induced by 2-B-2-MP. 2.3-dBPe. 2-BP. BE and 2-IP at 37 ${ }^{\circ} \mathrm{C}$ for $48 \mathrm{~h}$.

In Figure 3, chromatogram 1 indicates authentic guanine (Gua) at retention time of $4.82 \mathrm{~min}$ and chromatogram 2 indicates the mixture of dG and 5 -fluorouracil (5-FU) utilized as an internal standard at retention times of $8.38 \mathrm{~min}$ and $4.08 \mathrm{~min}$. respectively. Guanine. dG. and 5-fuorouracil were well separated from the biological background under the described chromatographic condition. Chromatogram 3.4.5.6. and 7 indicates the nixture after incubation of $\mathrm{dG}$ and excess amount (512 equivalent) of 2-B-2-MP. 2,3-dBPe. 2-BP. BE and 2-IP for $48 \mathrm{~h}$ at the physiological condition. respectively, which indicates the peak of retention time at $8.38 \mathrm{~min}$. which corresponds to the complete disappearance of $\mathrm{dG}$ and a peak of retention time at $4.82 \mathrm{~min}$. corresponding to the new appearance of guanine. These results indicated that complete deguanylation occurred when $d G$ was incubated with excess amount of 2-B-2-MP, 2.3-dBPe. 2-BP. BE, and 2-IP at $37{ }^{\circ} \mathrm{C}$ for $48 \mathrm{~h}$.

Analysis of deguanylation of guanosine induced by 2-B-2MP, 2,3-dBPe, 2-BP, BE, and 2-IP by HPLC. Figure 4 shows the HPLC chrontatograms under the chrontatographic condition described in material and methods. for the analysis of deguanylation of guanosine (Guo) induced by 2-B-2-MP, 2,3-dBPe. 2-BP, BE. and $2-\mathrm{IP}$ at $37^{\circ} \mathrm{C}$ for $48 \mathrm{~h}$.

In Figure 4, chromatogram 1 indicates authentic guanine (Gua) at retention time of $4.76 \mathrm{~min}$, and cluromatogram 2 indicates the mixture of guanosine and 5-fuorouracil (5-FU) utilized as an internal standard at retention times of $6.70 \mathrm{~min}$ and 4.06 nin, respectively. Guanine, guanosine and 5 -fluorouracil were well separated from the biological background under the described chromatographic condition. Clurontatogram $3,4,5,6$. and 7 indicates chromatogram of the mixture after incubation of guanosine and excess amount (512 equivalent) of 2-B-2-MP, 2.3-dBPe. 2-BP. BE, and 2-IP for 48 h at the physiological condition. respectively. which informs almost no change in amount of guanosine and no production of guanine at that condition by treatment of 2.3-dBPe. 2-BP. BE. and 2-IP (chromatogram 4, 5,6 and 7). However. in chromatogram 3. which corresponds to treatment of 2-B-2-MP. the peak of guanosine completely disappeared and a peak of retention time at $4.76 \mathrm{~min}$ corresponding to guanine newly appeared. The results indicated that deguanylation only occurred when guanosine was incubated with excess amount of 2-B-2-MP for $48 \mathrm{~h}$ at the physiological condition.

In Figures 2, 3, and 4, any change in amount of 5-fluorouracil during incubation of ddG. $d G$ and guanosine with 2-B-2-MP, 
(a) 2-B-2-MP

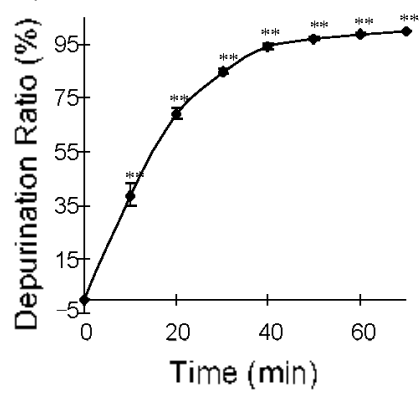

(b) 2,3-dBPe

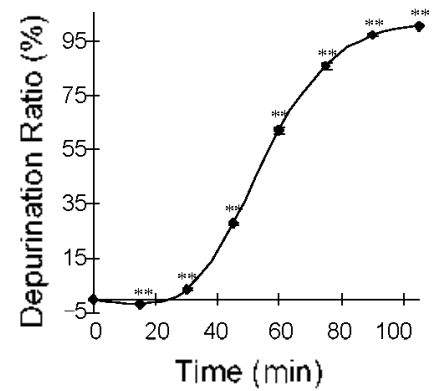

(c) 2-BP

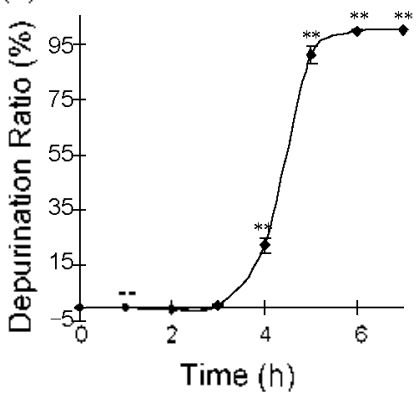

(d) $\mathrm{BE}$

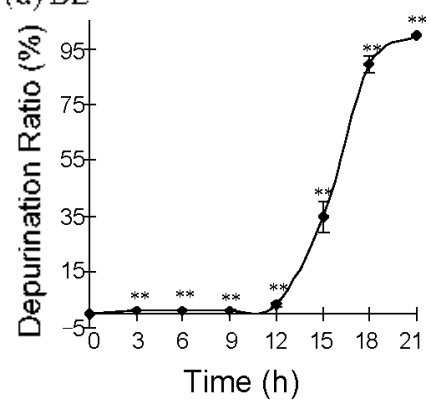

(e) 2-IP

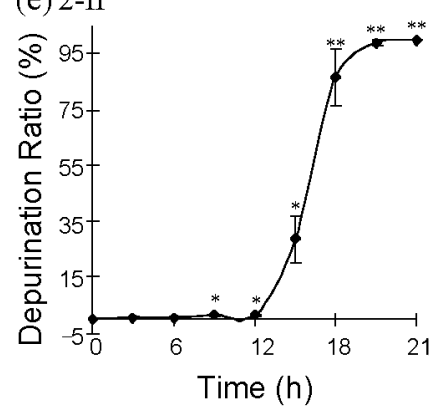

Figure 5. Time tesponse curves of ddG with (a) 2-B-2-MP (b) 2,3-dBPe (c) 2-BP (d) BE and (e) 2-IP. Tine response reactions were perfonmed with 4 equivalents of 2-B-2-MP and 512 equivalents of 2,3-dBPe, 2$\mathrm{BP}, \mathrm{BE}$ and 2-IP respectively until the time at which $100 \%$ deguany ation occurred. Then it was analyzed by HPLC following the condition mentioned in the materials and methods.

2,3-ABPe. 2-BP, BE and 2-IP was not observed. which indicates the concentration of 5 -fluorouracil was consistently well maintained and 5-fluorouracil was not affected by 2-B-2-MP, $2.3-$ dBPe. 2-BP. BE. 2-IP, or nucleosides.

Analysis of time response deguanylation of ddG induced by 2-B-2-MP, 2,3-dBPe, 2-BP, BE, and 2-IP. Figure 5 shows time response curves of deguanylation rate of $\mathrm{ddG}$ induced by $5 \mathrm{I} 2$ dose equivalent of 2-B-2-MP. 2.3-dBPe. 2-BP, BE, and 2-IP according to time. Figure $5(\mathrm{a})$ indicates time response curve of deguanylation after incubation of ddG and 512 dose equivalent of 2-B-2-MP at the phy siological condition at a time interval of $15 \mathrm{~min}$. Deguanylation begin to occur at $15 \mathrm{~min}$. and increase until 45 min in a time dependent manner. Complete deguanylation occurred at $60 \mathrm{~min}$. In Figure 5(b). corresponding to treatment with $2.3-\mathrm{dBPe}$, deguanylation begin to occur at 30 min. and drastically increase until $80 \mathrm{~min}$ in a time dependent (a) 2-B-2-MP

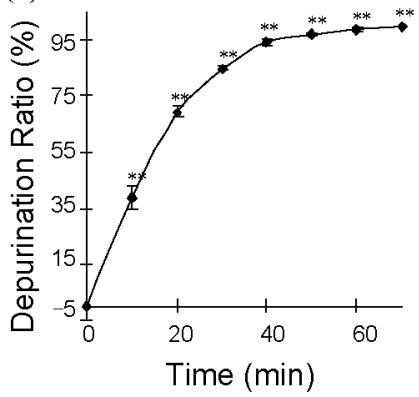

(b) $2,3-\mathrm{dBPe}$

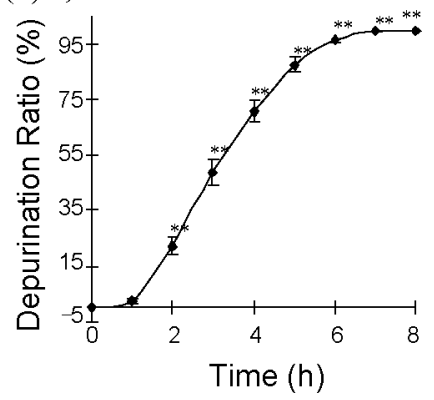

(c) 2-BP

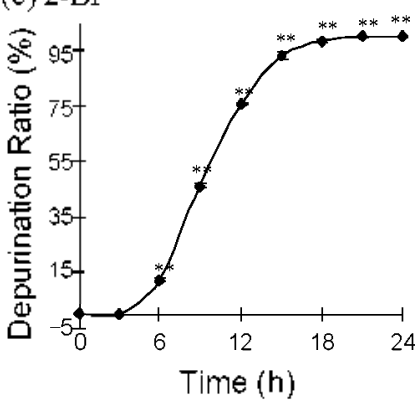

(d) $\mathrm{BE}$
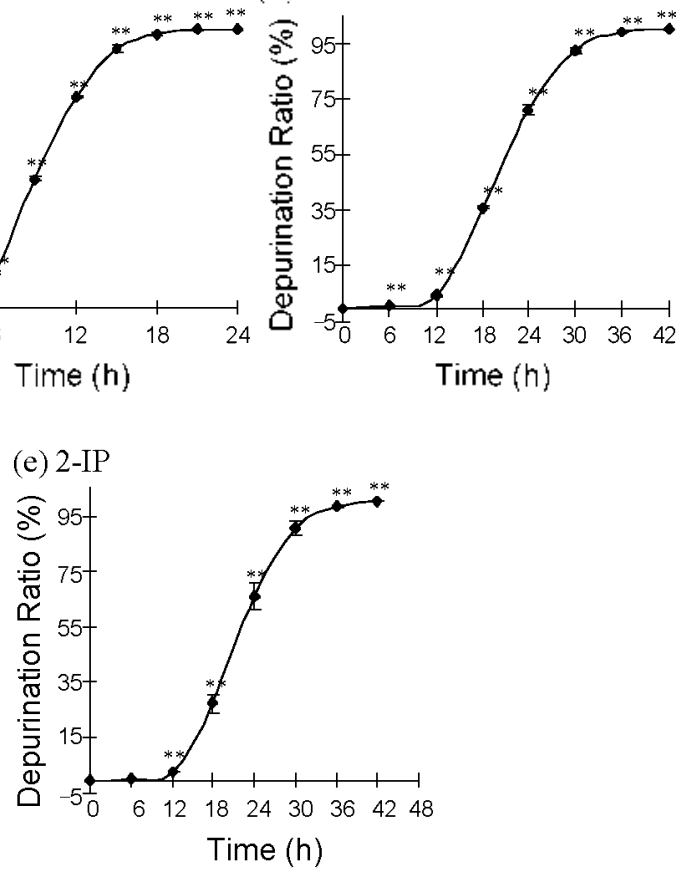

Figure 6. Time response curves of $\mathrm{dG}$ with (a) 2-B-2-MP (b) 2,3-dBPe (c) 2-BP (d) BE and (e) 2-IP. Time response reactions were performed with 32 equivalents of 2-B-2-MP and 512 equivalents of 2,3-dBPe, 2-BP, BE and 2-IP respectively until the time at which $100 \%$ deguany $1-$ ation occured. Then it was analyzed by HPLC following the condition mentioned in the materials and methods.

manner. Complete deguanylation occurred at 100 min. In Figure 5 (c). corresponding to treatment with 2-BP, deguanylation begin to occur at $3 \mathrm{~h}$, and drastically increase until $5 \mathrm{~h}$ in a time dependent manner. Complete deguanylation occurred at $6 \mathrm{~h}$. In Figure 5(d). corresponding to treatment with $\mathrm{BE}$. deguany lation begin to occur at $12 \mathrm{~h}$, and drastically increase until $18 \mathrm{~h}$ in a time dependent manner. Complete deguanylation occurred at $21 \mathrm{~h}$. In Figure 5(e). corresponding to treatment with 2-IP. deguanylation begin to occur at $12 \mathrm{~h}$, and drastically increase until $18 \mathrm{~h}$ in a time dependent manner. Conplete deguanylation occurred at 21 h. Compared to deguanylation rates in ddG anong $2-\mathrm{B}-2$ MP. 2.3-dBPe. 2-BP. BE. and 2-IP. the order of deguanylation mate was observed in 2-B-2-MP $>2.3-\mathrm{dBPe}>2-\mathrm{BP}>\mathrm{BE} \approx 2-\mathrm{IP}$. Especially, the deguany lation rates of 2-B-2-MP and 2.3-dBPe were much faster than that of 2-BP, BE and 2-IP.

Analysis of time iesponse deguanylation of $\mathrm{dG}$ induced by 


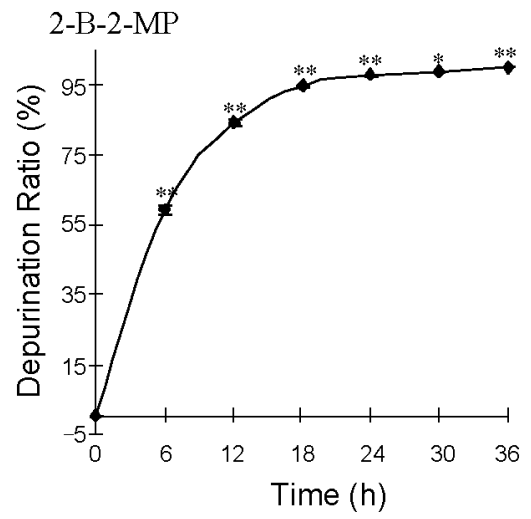

Figure 7. Time response curves of guanosine with 2-B-2-MP. Time response reactions were perfonmed with the 512 equivalents of $2-B-2-M P$ at a time interval of $6 \mathrm{~h}$ until the time at which $100 \%$ deguanvlation occurred. Then it was analvzed by HPLC following the condition mentioned in the materials and methods.

2-B-2-MP, 2,3-dBPe, 2-BP, BE, and 2-IP. Figure 6 shows time response curves of deguanylation rate of $\mathrm{dG}$ induced by 512 dose equivalent of 2-B-2-MP. 2.3-dBPe. 2-BP. BE and 2-IP according to time. Figure 6(a) indicates time response curve of deguanylation after incubation of $\mathrm{dG}$ and 512 dose equivalent of 2-B-2-MP at the physiological condition at a time interval of $10 \mathrm{~min}$. Deguanylation begin to occur at $10 \mathrm{~min}$. and drastically increase until $40 \mathrm{~min}$ in a time dependent manner. Complete deguanylation occurred at $60 \mathrm{~min}$. In Figure $6(\mathrm{~b})$. corresponding to treatment with 2.3-dBPe. deguanylation begin to occur at $1 \mathrm{~h}$ and drastically increase until $6 \mathrm{~h}$ in a time dependent manner. Complete deguanylation occurred at $7 \mathrm{~h}$. In Figure $6(\mathrm{c})$. corresponding to treatment with 2-BP. deguany lation begin to occur at $6 \mathrm{~h}$, and drastically increase until $15 \mathrm{~h}$ in a time dependent manner. Complete deguanylation occurred at $21 \mathrm{~h}$. In Figure $6(\mathrm{~d})$, corresponding to treatment with $\mathrm{BE}$, deguanylation begin to occur at $12 \mathrm{~h}$ and drastically increase until $30 \mathrm{~h}$ in a time dependent manuer. Complete deguanylation occurred at $36 \mathrm{~h}$. In Figure 6(e). corresponding to treatment with 2-IP. deguany'ation begin to occur at $12 \mathrm{~h}$ and drastically increase until $30 \mathrm{~h}$ in a time dependent manner. Complete deguanylation occurred at $42 \mathrm{~h}$. Compared to deguanylation rates in $\mathrm{dG}$ among 2-B2-MP. 2,3-dBPe, 2-BP. BE, and 2-IP, the order of deguanylation rate was observed in 2-B-2-MP $>2.3-\mathrm{dBPe}>2-\mathrm{BP}>\mathrm{BE} \approx 2-\mathrm{IP}$. Especially. deguanylation rate of 2-B-2-MP was much faster than that of 2-BP. BE. and 2-IP. Comparing deguanylation rates of $d d G$ and $d G$. the rate of ddG was faster than $d G$. In addition. the rate of deguanylation of guanine based-nucleosides was generally faster than deadeny lation of adenine based-nucleosides.

Analysis of time response deguanylation of guanosine induced by 2-B-2-MP. Figure 7 shows time response curve of deguanylation rate of guanosine induced by 512 dose equivalent of 2-B-2-MP at the physiological condition at a time interval of $6 \mathrm{~h}$. Deguanylation begin to occur within $6 \mathrm{~h}$ and drastically increase until $12 \mathrm{~h}$ in a time dependent manner. Complete degianylation occurred at $2+\mathrm{h}$. The rate of deguanylation of guanosine was much lower than that of ddG or dG.

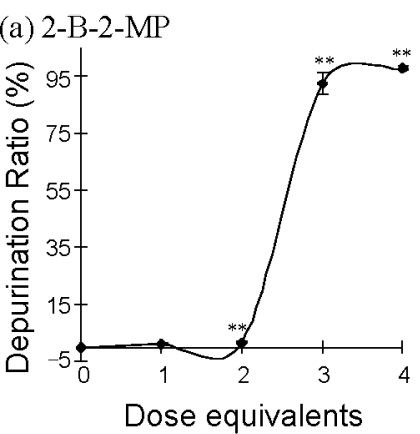

(b) 2,3-dBPe

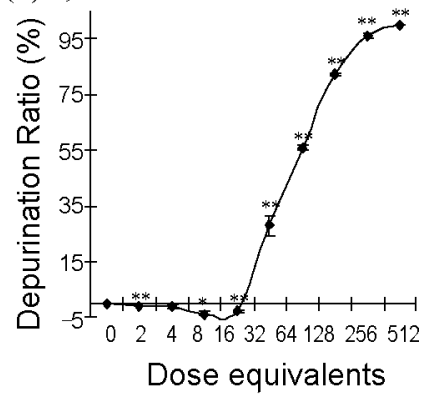

(c) 2-BP
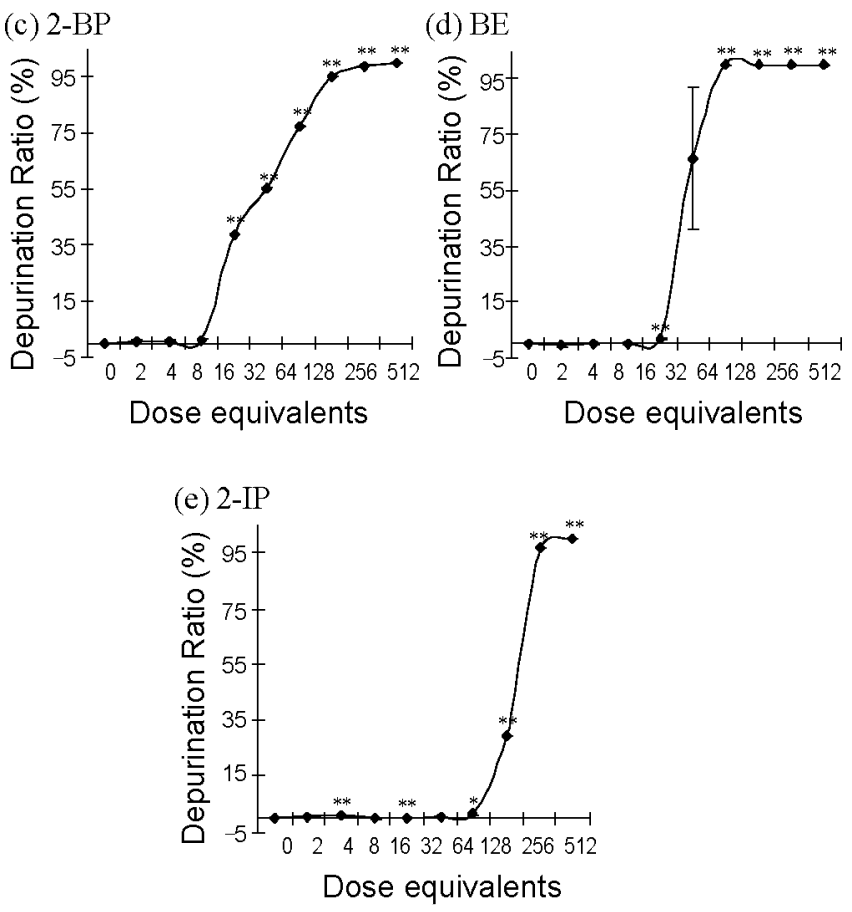

Figure 8. Dose response curves of ddG with (a) 2-B-2-MP (b) 2,3-dBPe (c) 2-BP (d) BE and (e) 2-IP. Dose response reactions were performed with the $0,2,4,8,16,32,64,128,256$ and 512 equivalents of halogenated alkanesfor a fixed time at which $100 \%$ deguanylation occurred. Then it was analyzed by HPLC under the condition mentioned in the materials and methods.

Analysis of dose response deguanylation of ddG induced by 2-B-2-MP, 2,3-dBPe, 2-BP, BE and 2-IP. Figure 8 shows dose response curves of deguanylation rates of ddG induced by 2 -B2-MP. 2.3-dBPe. 2-BP. BE and 2-IP according to dose. Figure 8 (a) indicates dose response curve of deguanylation after incubation of ddG and different dose equivalents of 2-B-2-MP at the phy siological condition for $24 \mathrm{~h}$. Deguanylation begin to occur at 1 dose equivalent of 2-B-2-MP. and drastically increase until 3 dose equivalent of 2-B-2-MP in a dose dependent manner. Conplete deguany lation occurred at 4 dose equivalent of 2-B-2-MP. In Figure 8 (b), corresponding to treatment with 2.3$\mathrm{dBPe}$. deguanylation begin to occur at 32 dose equivalent. and drastically increase until 128 dose equivalent in a dose dependent manner. Complete deguanylation occurred at 256 dose equivalent. In Figure 7(c). corresponding to treatment with 2 $\mathrm{BP}$. deguanylation begin to occur at 16 dose equivalent. and 
(a) 2-B-2-MP

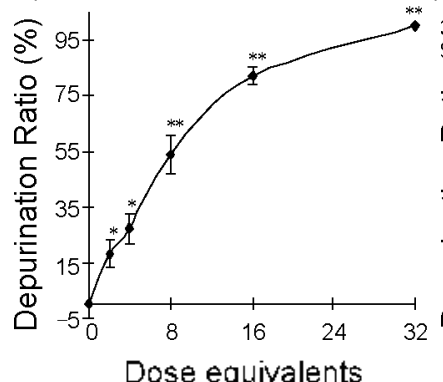

(b) $2, \hat{3}-\mathrm{dBPe}$

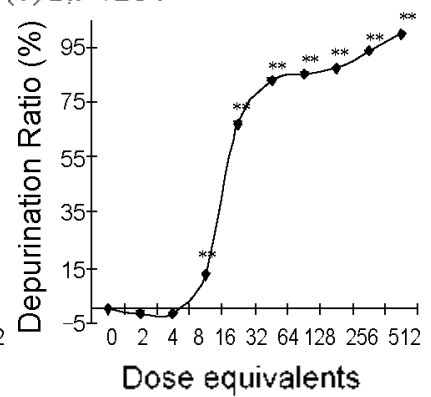

(c) 2-BP

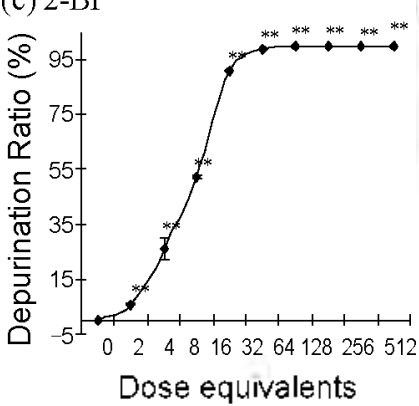

(d) $\mathrm{BE}$
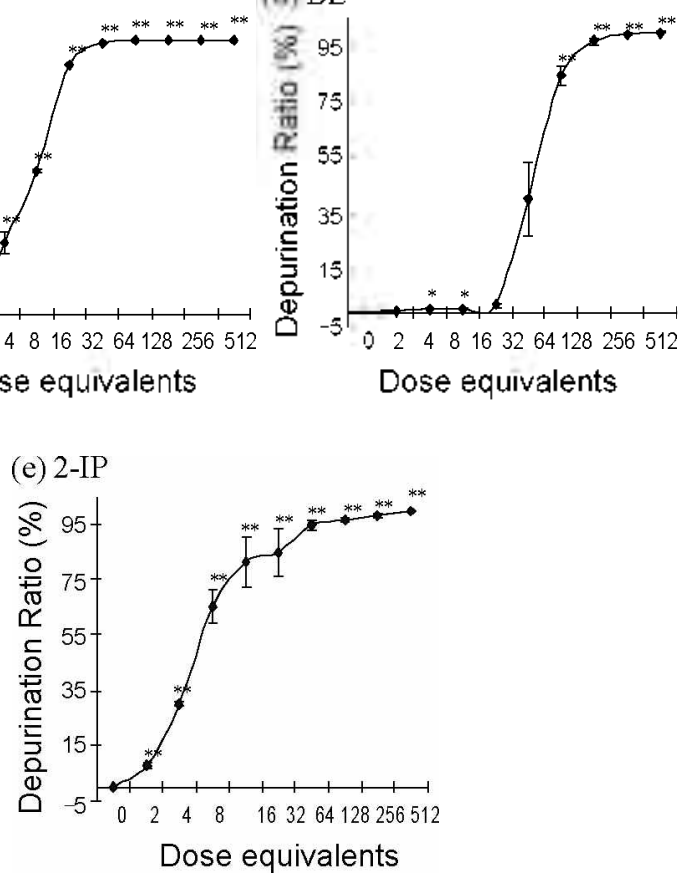

Figure 9. Dose response curves of dG with (a) 2-B-2-MP (b) 2,3-dBPe (c) 2-BP (d) $\mathrm{BE}$ and (e) 2-1P. Dose response reactions uere performed with the $0,2,4,8,16,32,64,128,256$ and 512 equivalents of halogenated alkanes for a fixed time at which $100 \%$ deguany lation occuned. then it was analy zed by HPLC under the condition mentioned in the materials and methods.

drastically increase until 128 dose equivalent in a dose dependent manner. Complete deguanỵlation occurred at 256 dose equivalent. In Figure 7(d), corresponding to treatment with $\mathrm{BE}$. degianylation begin to occur at 16 dose equivalent. and drastically increase until $6+$ dose equivalent in dose dependent manner. Complete deguanylation occurred at 64 dose equivalent. In Figure 7(e). corresponding to treatment with 2-IP. deguanylation begin to occur at 64 dose equivalent. and drastically increase until 256 dose equivalent in a dose dependent manner. Complete deguanylation occurred at 256 dose equivalent. Compared to deguanylation rates in ddG among 2-B-2-MP, 2.3dBPe. 2-BP. BE and 2-IP. the order of deguanylation rate was observed in $2-\mathrm{B}-2-\mathrm{MP}>2-\mathrm{IP} \approx 2-\mathrm{BP} \approx 2,3-\mathrm{dBPe} \geq \mathrm{BE}$.

Analysis of dose response deguanylation of $\mathrm{dG}$ induced by 2-B-2-MP, 2,3-dBPe, 2-BP, BE, and 2-IP. Figure 9 shows dose response curves of deguanylation rates of $\mathrm{dG}$ induced by 2-B-2-

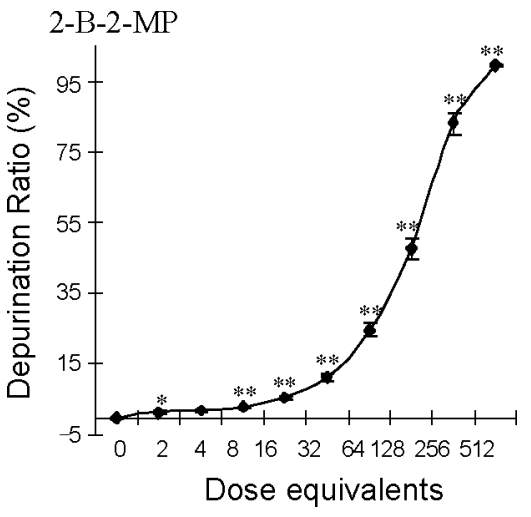

Figure 10. Dose response curves of guanosine with 2-B-2-MP. Dose response reactions were performed with the $0,2,4,8,16,32,64,128$. 256 and 512 equivalents of $2-B-2-M P$ for $36 \mathrm{~h}$. Then it was analyzed by HPLC underthe condition mentioned in the materials and methods.

MP. 2,3-dBPe. 2-BP. BE. and 2-IP according to dose. Figure 9 (a) indicates the dose response curve of deguanylation after incubation of $\mathrm{dG}$ and different dose equivalents of 2-B-2-MP at the phy siological condition for $24 \mathrm{~h}$. Deguanylation begin to occur at 2 dose equivalent of 2-B-2-MP. and drastically increase until 16 dose equivalent of 2-B-2-MP in a dose dependent manner. Complete deguanylation occurred at 32 dose equivalent of 2-B-2-MP. In Figure 9(b), corresponding to treatment with 2.3$\mathrm{dBPe}$. deguany lation begin to occur at 8 dose equivalent, and drastically increase until 32 dose equivalent in a dose dependent manner. Complete deguanylation occurred at 64 dose equivalent. In Figure 8(c). corresponding to treatment with 2-BP. deguanylation begin to occur at 2 dose equivalent. and drastically increase until 16 dose equivalent in a dose dependent manner. Complete deguanylation occurred at 32 dose equivalent. In Figure 8 (d), corresponding to treatment with $\mathrm{BE}$. deguanylation begin to occur at 16 dose equivalent, and drastically increase until 64 dose equivalent in a dose dependent manner. Complete deguanylation occurred at 128 dose equivalent. In Figure 7(e). corresponding to treatment with 2-IP. deguany lation begin to occur at 2 dose equivalent, and drastically increase until 16 dose equivalent in a dose dependent manner. Complete deguanylation occurred at 64 dose equivalent. Compared to deguanylation rates in dd $\mathrm{A}$ among 2-B-2-MP. 2.3-dBPe, 2-BP, BE. and 2-IP, the order of deguanylation rate was observed in 2-B-2$\mathrm{MP}>2-\mathrm{IP} \approx 2-\mathrm{BP} \approx 2,3-\mathrm{dBPe} \geq \mathrm{BE}$

Analysis of dose response deguanylation of guanosine ind uced by 2-B-2-MP. Figure 10 shows dose response curves of the deguanylation rate of guanosine induced by $2-\mathrm{B}-2-\mathrm{MP}$ according to dose at the phy siological condition for $36 \mathrm{~h}$. Deguanylation begin to occur at 8 dose equivalent of 2-B-2-MP, and drastically increase until 256 dose equivalent of 2-B-2-MP in a dose dependent manner. Conplete deguany lation occurred at 512 dose equivalent of 2-B-2-MP. The rate of deguanylation of guanosine was much lower than that of $\mathrm{ddG}$ or $\mathrm{dG}$.

LC-MS depurination analysis of calf thymus DNA induced by 2-B-2-MP. Figure 11 shows LC-MS depurination analy'sis of calf thynus DNA induced by $128 \mu \mathrm{L}$ of $2-\mathrm{B}-2-\mathrm{MP}$ for $48 \mathrm{~h}$ at the physiological condition under the LC-MS condition men- 
(a) RT. 0.00-24.99 SM. 7 B

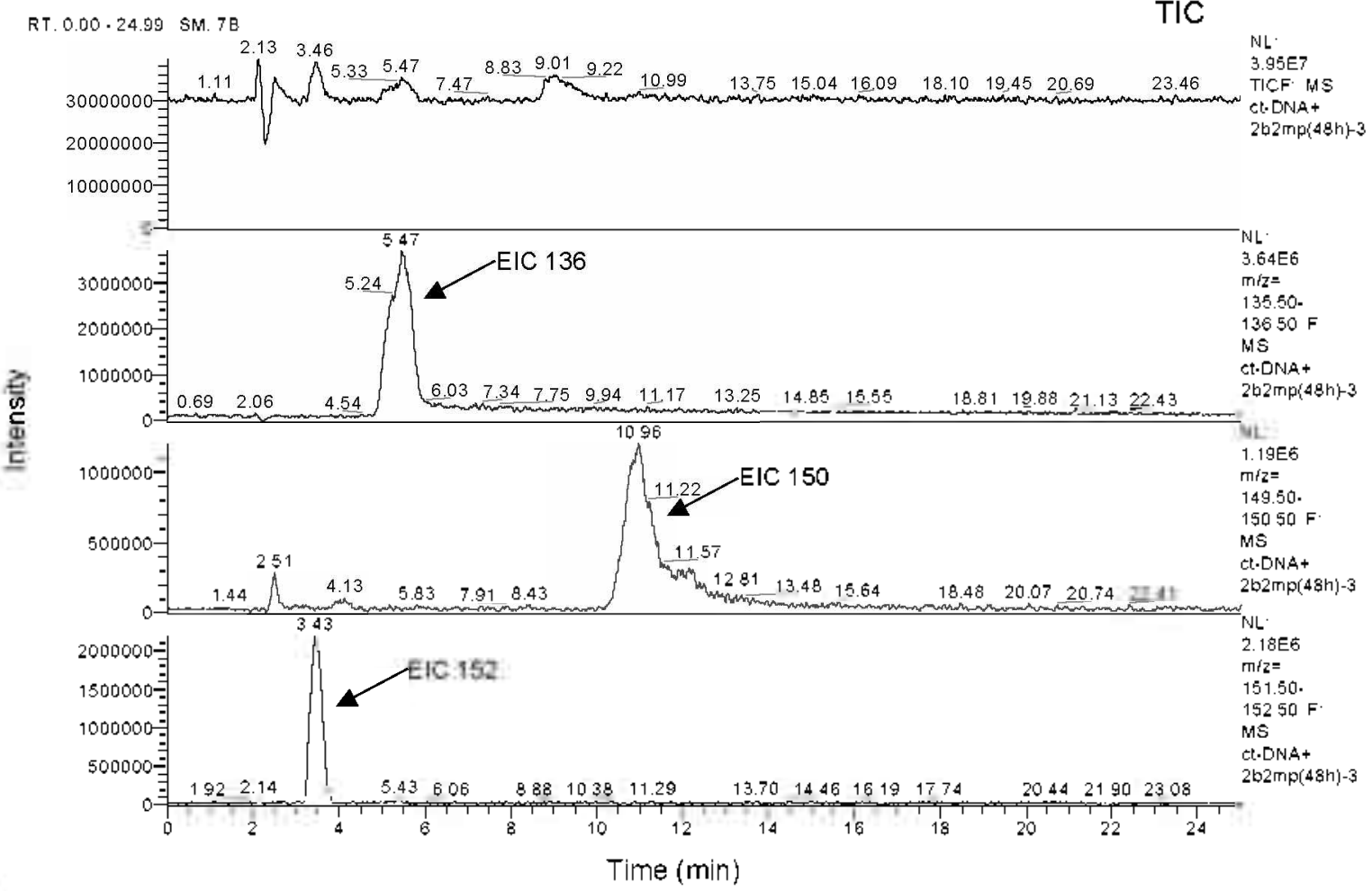

(b)

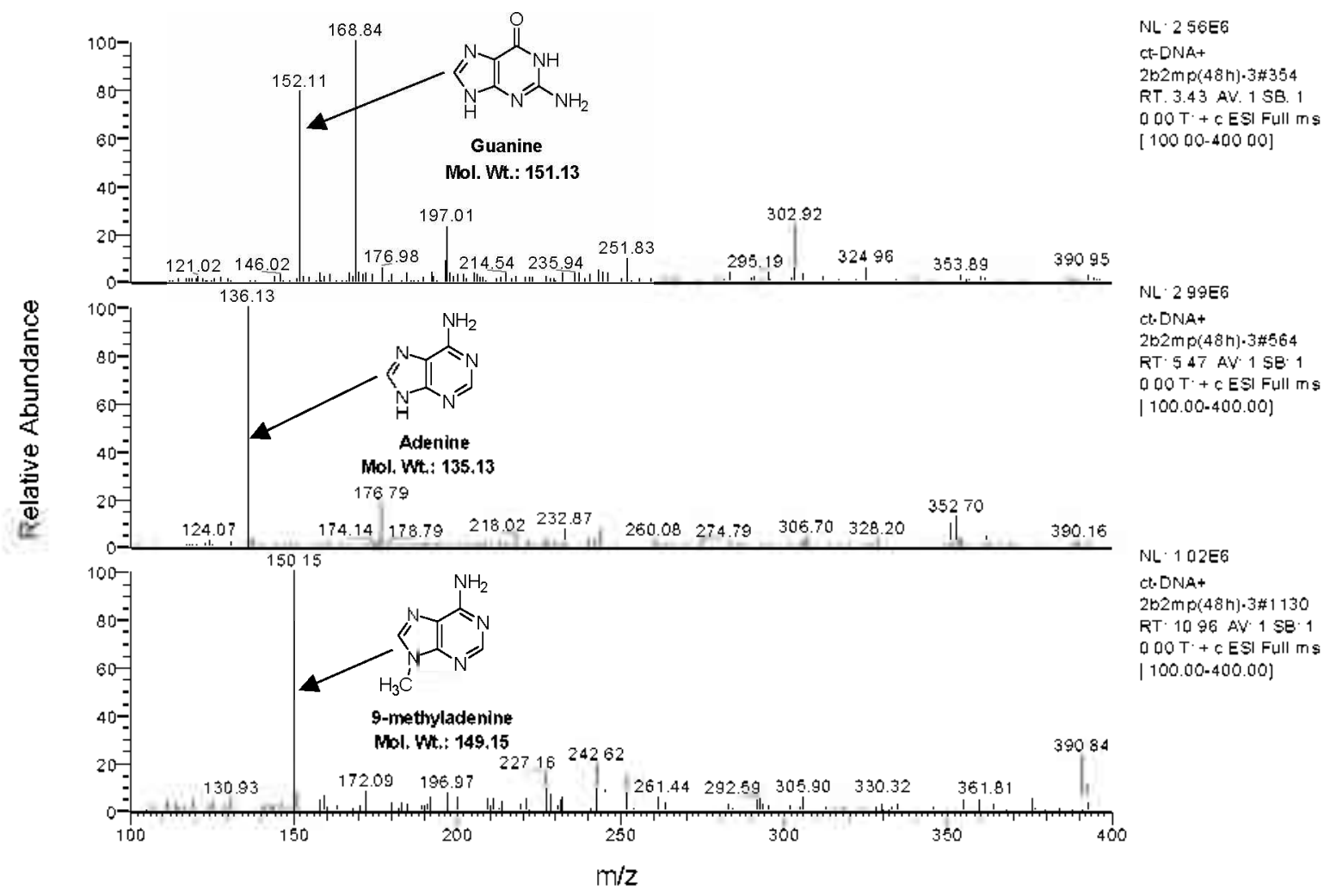

Figure 11. LC-MS analy sis of Ct-DNA with $128 \mu \mathrm{L}$ 2-B-2-MP for $48 \mathrm{~h}$ at the phy siological condition under the LC-MS condition mentioned in materials and methods. (a) LC-MS chromatogram. RT for Ade, Gua and 9-MA (intemal standard) are 5.47, 3.43 and 10.96 min, respectively. (b) ESI MS spectrogram. $[\mathrm{M}+\mathrm{H}]^{+}$peaks for Ade, Gua and 9-MA are 136.13, 152.11 and 150.15 , respectively.

tioned in materials and methods. Figure 11(a) shows LC-MS chromatogram of calf thy mis DNA treated by 2-B-2-MP under the above condition. In the total ion chromatogram (TIC). it is difficult to identify peaks of corresponding adenine. guanine, and 9-methyl adenine as an internal standard because of the formation of relatively small amounts of products along with many 


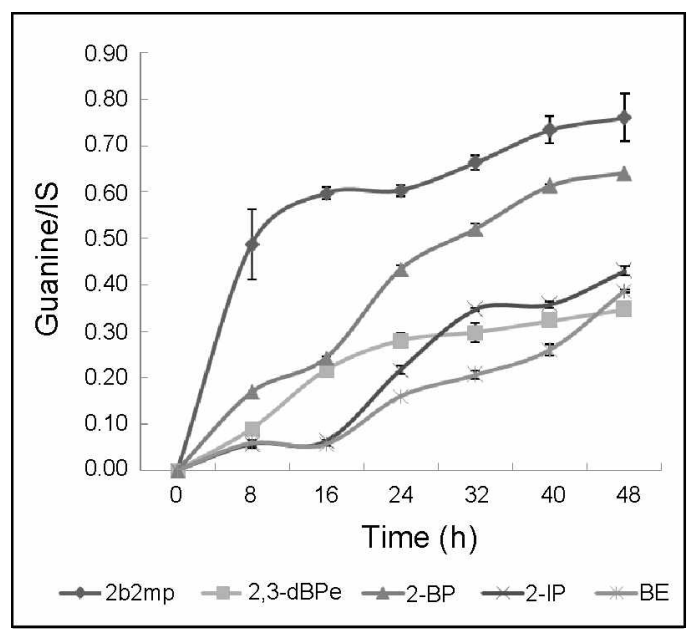

Figure 12. Time response curves of Ct-DNA for deguanylationwith 2-B-2-MP, 2,3-ABPe, 2-BP, BE and 2-IP. Time response reactions were perfomed with the $128, \mathrm{LL}$ of halogenated alkanes at a time interval of 8 h until 48 h.

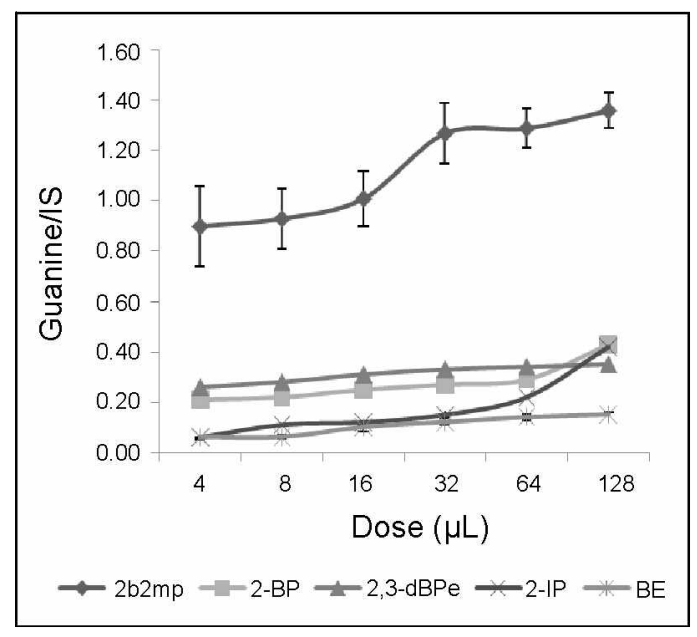

Figure 13. Dose response curves of Ct-DNA for deguanylationwith 2-B-2-MP, 2,3-dBPe, 2-BP, BE and 2-IP Dose response reactions were pertomed with the $2,4,8,16,32,64$ and $128 \mu \mathrm{L}$ of halogenated alkanes for $48 \mathrm{~h}$.

impurities. However. in the extracted ion chromatogram (EIC), the peak of retention time at 5.47 corresponding to adenine (EIC 136), the peak of retention time at 10.96 corresponding to 9-methyl adenine (EIC 150). and the peak of retention time at 3.43 corresponding to guanine (EIC 152), were well separated and displayed in a single peak in each EIC chromatogram. which was utilized for the analysis of time and dose response relationship. Figure 11(b) shows ESI MS spectrograms at EIC 152. EIC 136. and EIC 150. which corresponds to guanine. adenine. and 9-methyl adenine. respectively. The $[\mathrm{M}+\mathrm{H}]^{-}$peaks for adenine. guanine, and 9-methyl adenine are $136.13,152.11$, and 150.15 , respectively. With the same methods. LC/MS analyses of other haloalkanes were performed. and time and dose response deguanylation relationships induced by haloalkanes were additionally performed.
Analysis of time response deguanylation of calf thymus DNA induced by 2-B-2-MP, 2,3-dBPe, 2-BP, BE, and 2-IP. Figure 12 shows time response curves of the deguanylation rate of calf thymus DNA induced by 2-B-2-MP, 2,3-dBPe. 2-BP. BE, and 2-IP. according to time. The formation of guanine from calf thynus DNA by treatment with 2-B-2-MP, 2,3-dBPe. 2-BP, $\mathrm{BE}$, and 2-IP was observed in a time response manner. Compared to deguany lation rates in calf thymus DNA among 2-B-2$\mathrm{MP}, 2.3-\mathrm{dBPe}$. 2-BP, BE. and 2-IP. the order of deguanylation rate was observed in $2-\mathrm{B}-2-\mathrm{MP}>2-\mathrm{BP}>2,3-\mathrm{dBPe} \approx 2-\mathrm{P}>\mathrm{BE}$. Compared to the previously reported results, the rate of deguanylation in calf thymus DNA was much lower than that of deadenylation.

Analysis of dose response deguanylation of calf thymus DNA induced by 2-B-2-MP, 2,3-dBPe, 2-BP, BE, and 2-IP. Figure 13 shows dose response curves of deguanylation rate of calf thymus DNA induced by 2-B-2-MP. 2.3-dBPe. 2-BP. BE. and 2-IP. according to dose. The formation of guanine from calf thy mus DNA by treatment with 2-B-2-MP. 2.3-dBPe. 2-BP. BE. and 2-IP was observed in a dose response manner for $48 \mathrm{~h}$. Compared to deguany lation rates in calf thymus DNA among 2-B-2MP. 2.3-dBPe. 2-BP. BE. and 2-IP. the order of deguanylation rate was observed in $2-\mathrm{B}-2-\mathrm{MP}>2-\mathrm{BP} \approx 2,3-\mathrm{dBPe}>2-\mathrm{IP} \approx \mathrm{BE}$. Also the rate of deguany lation in calf thymus DNA was much lower than that of deadenylation.

\section{Discussion}

Deguanylation ratios (\%) in guanine based-nucleosides were calculated on the basis of the decreased anount of nucleosides in percentage by comparing the integration value of the nucleosides in HPLC using the formula mentioned in materials and methods. Since the solubility of guanine is relatively low at physiological condition, the guanine formed after deguany lation precipitates in a $\mathrm{pH} 7 .+$ buffer solution, which decreases the accuracy of deguanylation ratios. if we apply the increasing amount of deguanylated product (guanine) for the determination of deguanylation ratios. Therefore, we applied the decreasing amounts of nucleosides for the deternination of deguanylation ratios. Meanwhile. deguanylation ratios in calf thy mus DNA were calculated on the basis of the increased amount of guanine by comparing the integration value between increased guanine and the intemal standard in EIC from LC-MS/MS using the fornula mentioned in materials and methods. Since guanine is soluble in acidic condition, $1 \mathrm{M}$ aqueous $\mathrm{HCl}$ was added to dissolve the precipitated guanine before analysis.

In Figures 2. 3. and 4. chromatogran 1 shows the peak of authentic guanine as a reference. chromatogram 2 shows that of guanine based-nucleosides. ddG, dG. or guanosine, along with the peak of internal standard. and chromatogram $3,4.5$. 6 . and 7 show the peaks of products fonmed after incubation of $\mathrm{ddG}, \mathrm{dG}$, or guanosine with 2-B-2-MP. 2,3-dBPe, 2-BP, BE, and 2-IP for $48 \mathrm{~h}$. respectively. It is evident that the peaks of $\mathrm{dd} G$ and $\mathrm{dG}$ completely disappeared and the peaks of guanine have appeared after incubation with 2-B-2-MP. 2.3-dBPe. 2-BP. $\mathrm{BE}$, or 2-IP for $48 \mathrm{~h}$ (chromatogram $3,4,5,6$, and 7 in Figures 2 and 3). However. almost no change of chromatogram was observed after incubation of guanosine with 2.3-dBPe. 2-BP. 
$\mathrm{BE}$, and 2-IP for 48 h (chromatogram 4. 5, 6, and 7 in Figure 4). Meanwhile, in chromatogram 3 in Figure 4 , which corresponds to treatment of 2-B-2-MP and guanosine. the peak of guanosine completely disappeared, and the peak of guanine appeared. which indicates that deguanylation only occurred when guanosine was incubated with excess amount of 2-B-2-MP for $48 \mathrm{~h}$ at the physiological condition. whereas almost no deadenylation was observed for adenosine by treatment of $2-\mathrm{B}-2-\mathrm{MP}$ at the same condition.

Time and dose response reaction with $\mathrm{ddG}$ and $\mathrm{dG}$ by $2-\mathrm{B}$ 2-MP, 2,3-dBPe, 2-BP, BE. and 2-IP. and also with guanosine by 2-B-2-MP indicate that deguanylation increased in a time and dose dependent manner (Figures 5, 6. 7. 8, 9, and 10). According to time (Figures 5 and 6), the order of deguanylation rate among halogenated alkanes was observed as $2-\mathrm{B}-2-\mathrm{MP}>2.3-\mathrm{dBPe}>$ $2-\mathrm{BP}>\mathrm{BE} \approx 2-\mathrm{IP}$ in both ddG and dG. Especially. deguany lation rate of 2-B-2-MP was mich faster than that of 2-BP. BE and 2-IP. Comparing deguanylation rates of ddG. dG, and guanosine. the rate of $\mathrm{ddG}$ was faster than $\mathrm{dG}$. followed by guanosine. ${ }^{18}$ According to dose (Figures 8 and 9). the order of deguanylation rate among halogenated alkanes was observed as $2-\mathrm{B}-2-\mathrm{MP}>2-\mathrm{IP} \approx 2-\mathrm{BP} \approx 2.3-\mathrm{dBPe} \geq \mathrm{BE}$ in both ddA and $\mathrm{dA}$. Similary, deguanylation rate of 2-B-2-MP was much faster than that of 2-BP. BE and 2-IP. which indicated that the rate of deguanylation in tertiary halide was highest. followed by secondary and primary halide.

Time and dose response reaction with calf thy mus DNA by 2-B-2-MP, 2,3-dBPe, 2-BP, BE, and 2-IP indicated that deglany lation increased in a time and dose dependent manner (Figures 12 and 13). The order of deguany lation rate was observed in $2-\mathrm{B}-2-\mathrm{MP}>2-\mathrm{BP}>2.3-\mathrm{dBPe} \approx 2-\mathrm{IP}>\mathrm{BE}$ in time response reactions. and $2-\mathrm{B}-2-\mathrm{MP}>2-\mathrm{BP} \approx 2.3-\mathrm{dBPe}>2-\mathrm{IP} \approx \mathrm{BE}$ in dose response reactions. Comparing rates of deadenylation and deglanylation in calf thymus DNA. the rate of deadenylation was much higher than that of deguanylation. This result may be explained by the fact that guanine is bound to cy tosine with three $\mathrm{H}$-bonds whereas adenine is bound to tlymine with two $\mathrm{H}$-bonds in double stranded DNA. which makes adenine easier to detach from the chain. ${ }^{3}$

\section{Conclusion}

Among the sixteen halogenated alkanes. we observed that five halogenated alkanes (2-B-2-MP. 2,3-dBPe, 2-BP, BE and 2-IP) induced deguanylation of $\mathrm{ddG}$ and $\mathrm{dG}$, and 2-B-2-MP also induced deguany lation of guanosine as a probable mechanism of toxicity. 2-B-2-MP showed the highest deguanylation rate compared to the other halogenated alkanes. which indicates that tertiary alkyl halides display greater reactivity than secondary alkyl halides, followed by primary alkyl halides. It was also observed that ddG showed the highest reactivity, followed by $\mathrm{dG}$ and guanosine. Although the exact mechanism of deguanylation is not known. our results show that the hydroxyl group in the sugar moiety of the nucleosides plays an important role regarding the rate of deguanylation. The study which aims to elucidate the mechanism of deguany lation induced by halogenated alkanes is in progress.

Aclonowledgments. This work was supported by Basic Science Research Program through the National Research Foundation of Korea (NRF) funded by the Ministry of Education. Science and Technology (RII-2007-040-02004-0).

\section{References}

1. Kunkel, T. A. Proc. Natl. Acad. Sci. LS S 1984, 81, 1494

2. Vousden, K. H.; Bos, I. L.; Marsheall, C. J.: Phillips, D. H. Proc. Vatl Acad Sci. LSA 1986, 83, 1222.

3. Drake, J. W.; Baltz, R. H. Annu. Rev Biochem 1976, 45,11 .

4. Schaaper, R. M.: Leob. L. A. Proc. Natl .Acad Sci. US 1 1981, 78, 1773 .

5. Lucas, L. T.: Gatehouse, D.: Shuker, D. E. G. J. Biol Chem. 1999. 274,18319

6. Sherchan, J.; Choi, H.; Lee, E. S. Bull. Korean Chent. Soc, 2009. $30(10), 2309$

7. Sherchan, I.; Yun, M.; Lee, E. S. Bull Korean Chem. Soc 2009, $30(10), 2318$

8. Lag, M:; Omichinski, J. G.; Dybing, E.; Nelson, S. D.; Soderlund, E. J. Chem. Res. Toxicol 1994, 93,73.

9. Iones, A. R.; Fakhouri, G.; Gadiel, P. Experientia. 1979, $35,1432$.

10. Jones, A. R.; Wells, G. Xenobiotica. 1981, 11,541.

11. James, S. P.; Pue, M. A.; Richards, D. H. Toxicol Lett. 1981, 8, 7.

12. Tachizawa, H.: MacDonald, T. L.: Neal, R. A. Mol Phamacol. $1982,22,745$

13. Volp, R. F,; Sipes, I. G.; Falcoz, C.; Carter, D. E.; Gross, J. F. Toxicol. Appl. Phamacol 1984, 75,8.

14. Dybing, E.; Onichinski, J. G.; Saderlund, E. J ; Brunborg, G.; Lag, M.; Holme, J. A.: Nelson, S. D. Reviews in Biochemical Toxicologv; Hodgson, E.; Bend, I. R.; Philpot, R. M., Eds.; Elsevier Science Publishing: New York, 1989; vol. 10, p. 139

15. Pearson, P. G.; Omichinski, J. G.; Myers, T. G.; Soderlund, E. T. Dybing, E.: Nelson, S. D. Chem. Res. Toxicol. $1990,3,458$.

16. Pearson, P. G.: Soderlund, E. J,; Dybing, E; Nelson, S. D. Biochemistry 1990, 29,4971.

17. Cmarik, J. L.; Inskeep, P. B.; Meredith, M. J.; Meyer, D. T.; Ketterer, B.; Guengerich, F. P. Cancer Res. 1990, 50, 2747.

18. Zoltewicz, T. A.: Clark, D. F.: Sharpless, T. W.; Grahe, G. J. Am. Chem. Soc. 1970. 92, 1741

19. York, J. L. J. Org. Chent. 1981, 46, 2171.

20. Garrett, E. R; Mehta, P. T. J. Ant. Chem. Soc. 1972, 94, 8542. 